\title{
Development of an Ultralight with a Ducted Fan
}

\author{
Jiří Brabec, Martin Helmich \\ Department of Aerospace Engineering, Faculty of Mechanical Engineering, CTU, Karlovo namesti 1, 121 35, Prague 2, \\ Czech Republic
}

Corresponding author: helmich@aerospace.fsik.cvut.cz

\begin{abstract}
This paper introduces the UL-39 project, an ultralight aircraft with a ducted fan, and some of the problems that have arisen in the course of its development. Several problems with the design of a non-traditional aircraft of this kind are mentioned, e.g. the design of the airframe, and the design of the propulsion unit. The paper describes the specific procedure for determining the basic thrust characteristics of this unusual aircraft concept, and also the experimental determination of these characteristics. Further options for applying the experience gained during the work, and the future focus of work on these issues, are outlined at the end of the paper.
\end{abstract}

Keywords: available thrust, required thrust, propulsion, ducted fan.

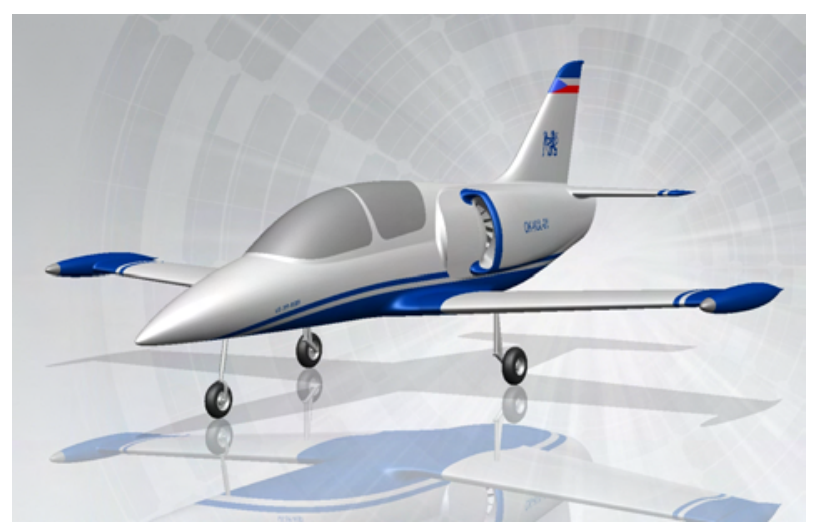

Figure 1: UL-39 model.

\section{Introduction}

About 12 years ago, the idea of building an ultralight aircraft powered by a ducted fan arose at CTU in Prague. An airplane of this type would offer the feeling of jet-powered flight to a relatively large population at a very much lower cost than a real jet plane. At the same time, it would enable higher maximum speed than is usual for planes in this category with propellers. The existence of such an engine would also provide an impulse for the market to further improve its production, which has now stabilized at a certain level and has not been developing any further.

In the past, a number of aircraft were constructed which attempted to use either a ducted fan or a propeller in a ring. In most cases, these were amateur efforts with insufficient theoretical support, or with inadequate financial support, which in the end were unsuccessful.

The technical possibilities that have become available in recent years, especially the existence of rel- atively light and highly effective high-speed engines and significant developments in composite technologies, have enabled the construction of an airplane of this type under conditions accessible to producers of ultralights.

A number of problems have arisen during the development of this type of aircraft that we do not face when developing a "regular" ultralight, and which require a non-traditional or completely new solution. Some aspects of the design of this aircraft, and work being done on developing it, will be described here.

\section{Specifications of the airframe design}

Even the conception of such an aircraft poses certain difficulties when compared with propeller airplanes, especially when it comes to designing the size of the aircraft. This then has a significant effect on the weight of the aircraft. The most difficult task is to keep to the weight limits determined by the construction regulations. The target weight category for these aircraft is limited to a maximum take-off weight of $472.5 \mathrm{~kg}$, if using a parachute rescue system (or $450 \mathrm{~kg}$ without a parachute rescue system). Taking into acccount all variable weight items, such as pilots and fuel, we are left with about $320 \mathrm{~kg}$ for the airframe and the power unit.

Where can we save construction weight? Because the size of the fuselage is given by the size of the ducted fan power unit and the necessity to locate the staff there, it cannot be changed significantly. Savings have to be found first on the wings. Minimization of the wing area required the use of aerodynamic profiles reaching high maximum lift coefficient values and using highly effective high-lift systems [1]. This resulted 


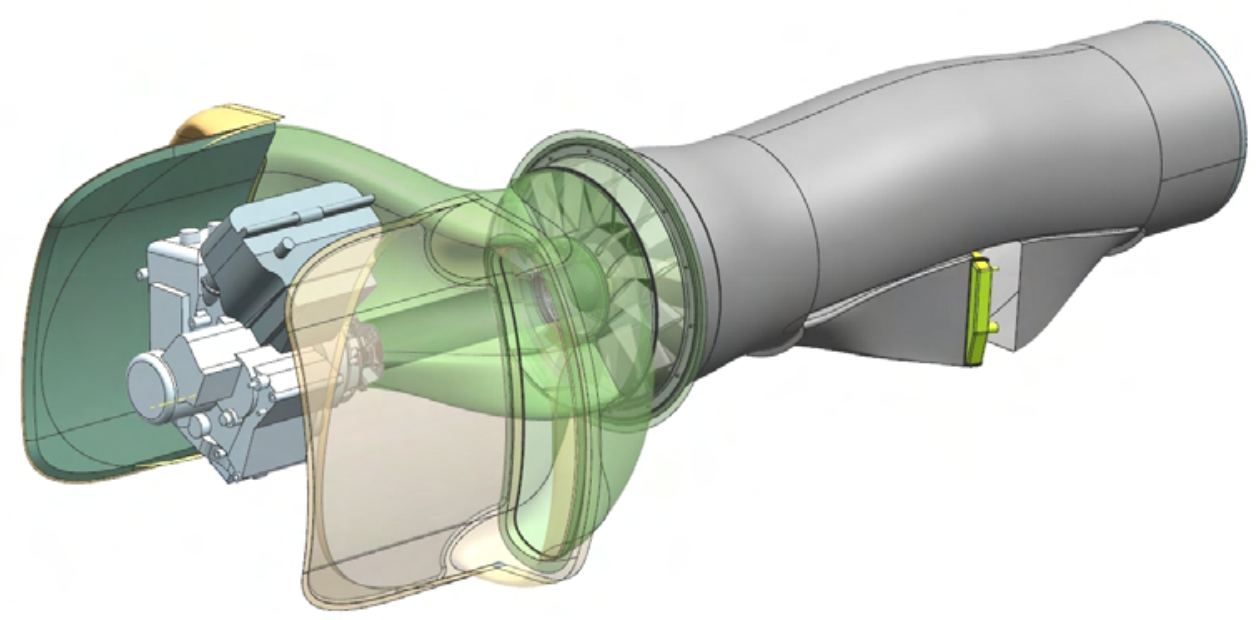

Figure 2: Real set up of the aircraft propulsion.

in a wing area that is $20 \%$ smaller than usual for this category of two-seater aircraft, and the wing is about $20 \%$ lighter than competitive wings. Another way to lower the weight is by using progressive technologies and light-weight materials.

\section{Conceptual set-up of the power unit}

The main use of the propeller is as a means for converting the energy to gain thrust in the ultralight category of "relatively low" weight airplanes. Considering the differences, and attempting to create a new concept for an ultralight aircraft, while keeping to the certification criteria, we end up with the thought of using a non-conventional power unit in this category: propulsion with a fan in the outlet channel, i.e. a cold propulsor. This is a construction type that crosses the border from propeller to jet propulsion.

The whole propulsion system consists of the inlet channel one-stage low pressure axial fan with a stator blade powered by a transmission shaft in a piston engine and an outlet channel with a jet.

The propulsion set up is a dominant feature of the structure, in which the inlet and the outlet channel form another internal integral sandwich structure of the aircraft fuselage. After long consideration, we selected for the heart of the power unit a four-cylinder motorcycle petrol engine, volume $999 \mathrm{~cm}^{3}$ sed in a BMW S1000RR motorcycle with motor power of max. approx. $200 \mathrm{k}$ (see [3]).

\section{Technologies used}

Due to placing the outlet channel in the fuselage of the plane and therefore increasing the weight of the airplane, and due to the necessity to comply with the weight limits for the selected construction regulations, the structure uses composite materials. Contact lamination is currently the standard production technology in producing the parts of ultralight airplanes that are made of composite materials. Contact lamination causes differences in the weight of the components and in their mechanical characteristics. At the same time it introduces a risk of low temperature tolerance.

All these factors, together with the idea of creating a really unique plane, led to the use of autoclave technology with prepreg materials regularly used in the construction of army airplanes or airplanes in the General Aviation category. Up to now, though, autoclave technology had never been used in an airplane in the ultralight category (UL).

\section{Determining the thrust characteristics}

In the course of developing a non-traditional airplane of this kind, a number of problems arise that are not directly connected with the structure itself, but which in the end influence it quite significantly. To determine the dimensions of most load-bearing parts of the structure, it is necessary to know the maximum speed that the aircraft can reach during horizontal flight. To determine the maximum speed, it is necessary to know the thrust characteristics of the power unit and 


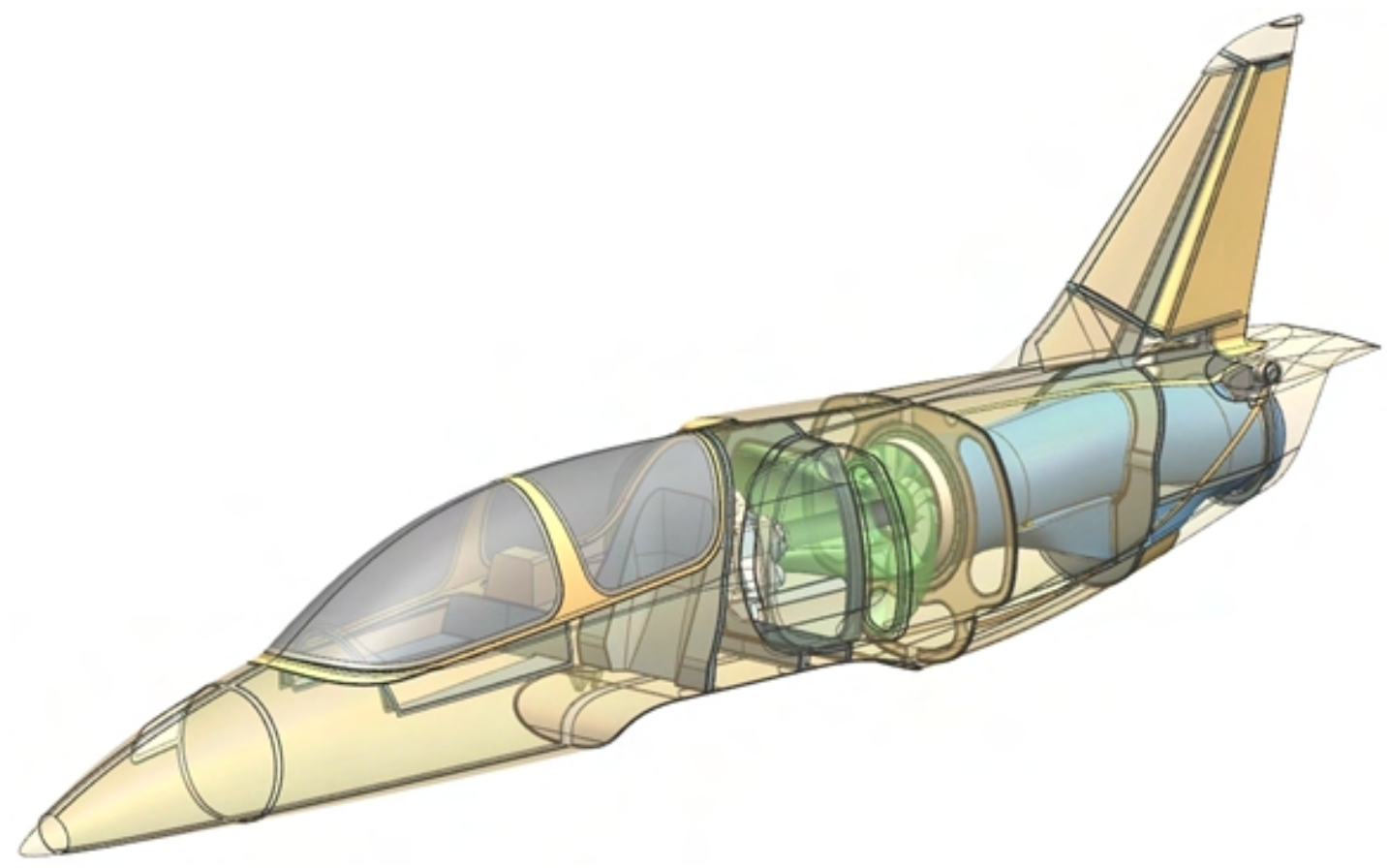

Figure 3: Locating the power unit in the fuselage.

the drag characteristics of the plane. These characteristics are represented by values called available thrust, i.e. the thrust that the plane can use for a specific flight speed, and the required thrust for the plane drag.

Both these values depend greatly on flight speed. For a regular plane (with a propeller), both of these values can be determined using empirical relations, which generally correspond well with the real values. For a plane with a ducted fan power unit, the situation is slightly different, but very similar, if not practically the same, as with a jet airplane. In this case, quite a strong effect on the drag characteristics of the plane is caused by the presence of the power unit. It is very difficult, if not impossible, to employ the simple calculation procedures that can be used with a propeller airplane. Because the available thrust is greatly affected by the power unit regime (and is so dependent on the available thrust), it is not possible to solve this problem individually, which is the regular procedure with propeller propulsion. The procedure currently used to deal with this issue will be described below.

The dependencies mentioned below will for now be mentioned without measures, without real values, which should not be published at this point in the project.

\subsection{Methodology for determining the maximum speed}

First, the necessary values were determined on the basis of the empirical relations (in the case of the airframe) and CFD analysis (in the case of the power unit). Generally, the required thrust of the power unit is determined as the sum of the contributions of the individual aircraft parts to the total drag power. In the calculation, the drags of the elementary parts of the airplane were considered, e.g. fuselage, wing, tailplane, landing gear, canopy and air inlets. The theoretical courses of these values are marked in Fig. 4. The maximum speed value is given by the meeting point of the curves of the available and required thrust in Fig. 4 (curves Tp and Tv). As mentioned above, this is where we encounter the problem of determining the real values of the required and available thrust. Determining the drag of the plane using the regular procedure does not take into consideration how it is influenced by the thrust of the power unit. In addition, theoretical determination of the available thrust of the power unit can be considered very difficult and inaccurate, due to lack of experience with procedures of this kind.

In the Czech Republic, this problem has undoubtedly been solved several times in the development of jet planes, but this was always in military applications and the results are therefore not available to the development team.

After long discussions about the methodology for determining the real performance parameters of the propulsion unit and the required thrusts to power the plane, we decided to make an experimental determination of the required characteristics and a compilation of the methodology to determine the available and required thrust theoretically. 


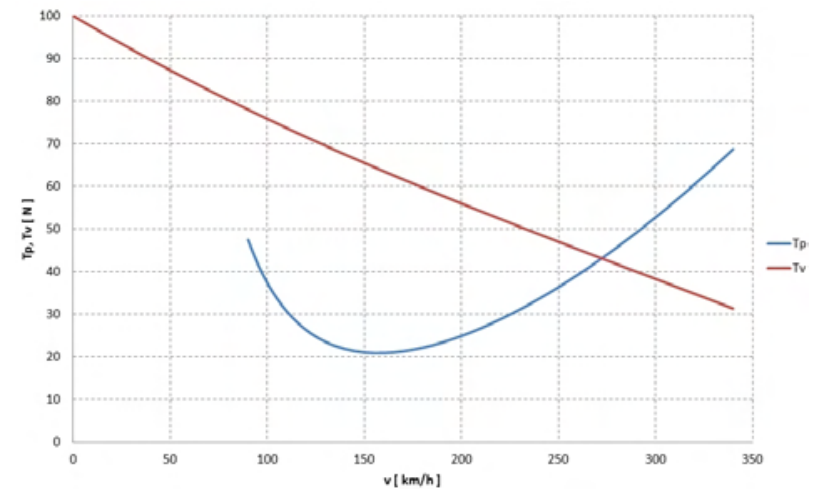

Figure 4: Equiponderant thrust diagram.

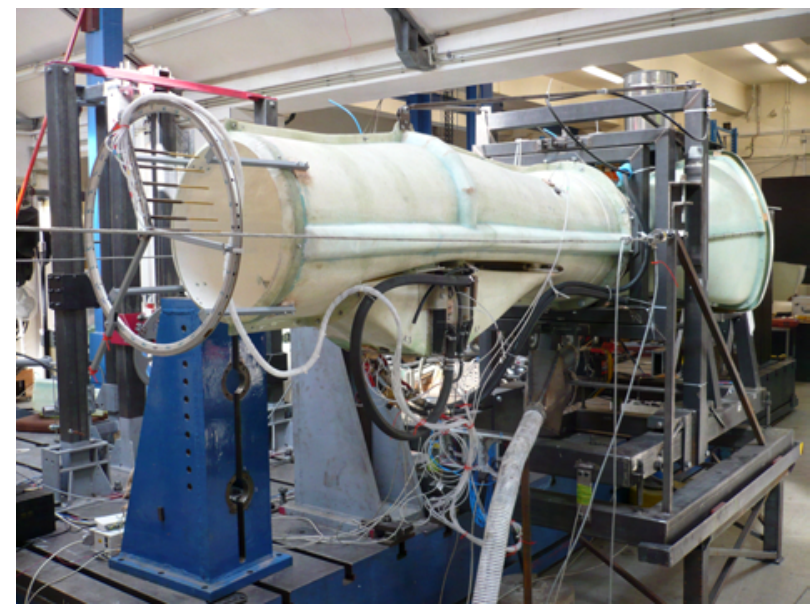

Figure 5: View of the back part of the static stand for tests on the new power unit under laboratory conditions.

\subsection{Determining the thrust characteristics on a static test bed}

The first necessary and logical step for the successful development of the new aircraft concept was to manufacture a static test bed located in a laboratory. This test bed is intended for static measurements (without forward speed), for determining the functionality of the system, for investigating the thrust characteristics for several different configurations, and making comparisons with the theoretical values obtained while developing the propulsion unit.

The core of the test bed was the engine designed for the Yamaha YZF-R1 2004, a 180 HP sports motorbike. That was the previous choice of power plant before the BMW engine.

This demonstrator of the aircraft propulsion unit enabled us to measure important propulsion system parameters for configurations with one or two coolers placed in the outlet channel, varying the outlet nozzle diameters, etc.

The most valuable data, e.g. thrust, was de-

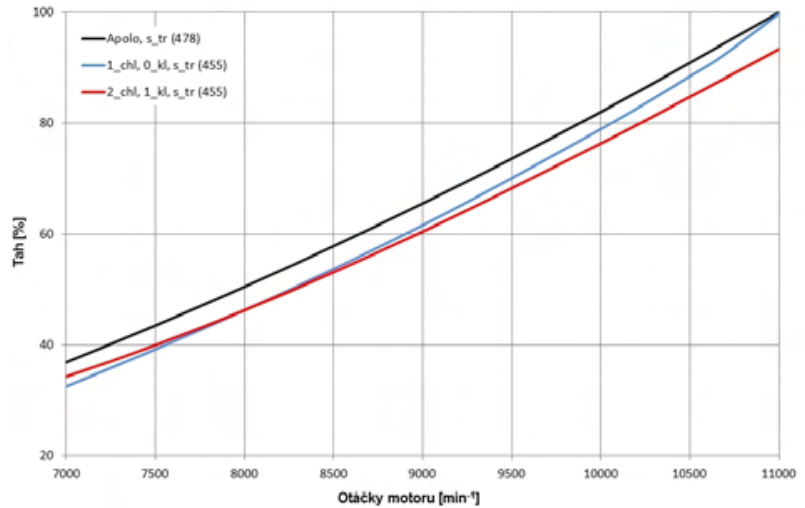

Figure 6: Example of the performance characteristics of the stand.

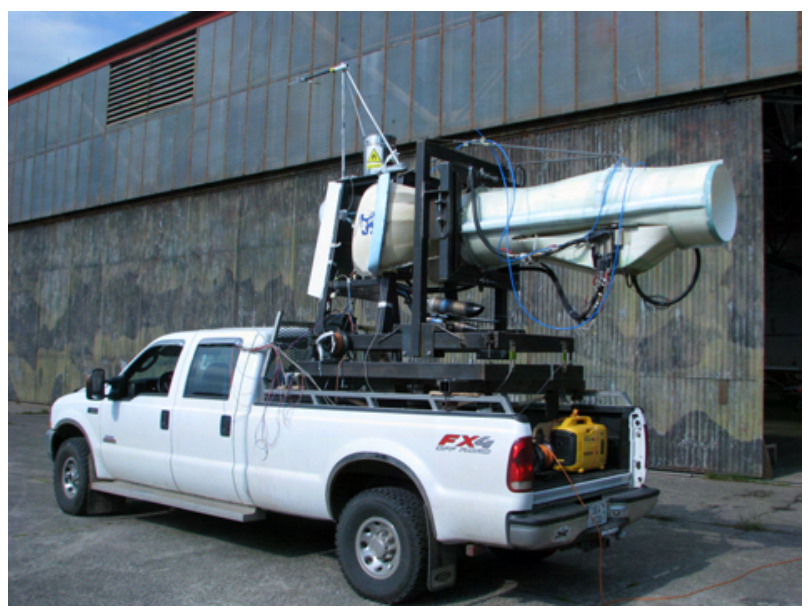

Figure 7: Mobile tests of the propulsion unit with a Ford car.

termined by dynamometers and metal planchettes equipped with a tensometric gauge. The velocity and pressure field in the outlet nozzle were investigated according to engine or fan revolutions. From the operational point of view, the temperatures on the rotor bearings, near the coolers, the exhaust system and the engine compartment are all insignificant parameters. Other measured parameters were the fuel consumption and the volume flow of coolant in the cooling system.

The dependency of available thrust on motor speed in different propulsion variations is shown in Fig. 6.

\subsection{Determining the thrust characteristics during mobile tests}

Although the previous measurements provided a number of very valuable operational and performance parameters, it was now necessary to obtain characteristics on speed. This was absolutely necessary for further development of the flying prototype. For this 


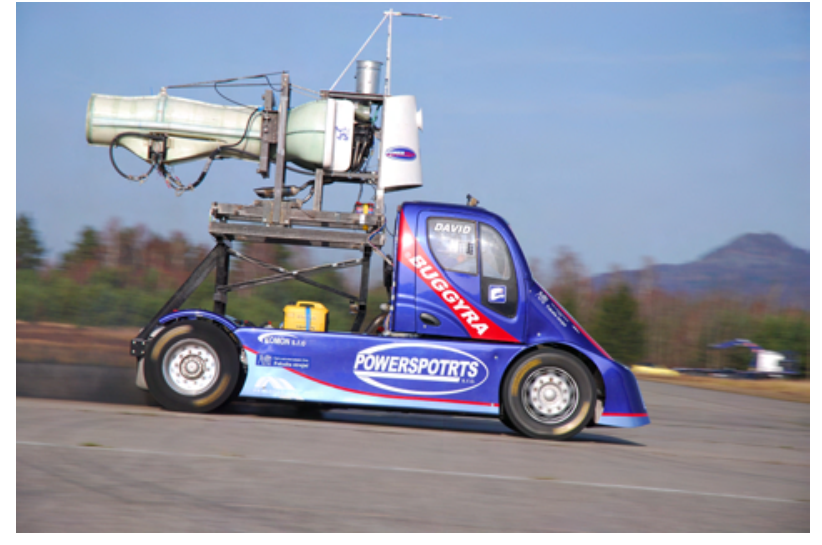

Figure 8: Mobile tests of the propulsion unit with a Buggyra truck.

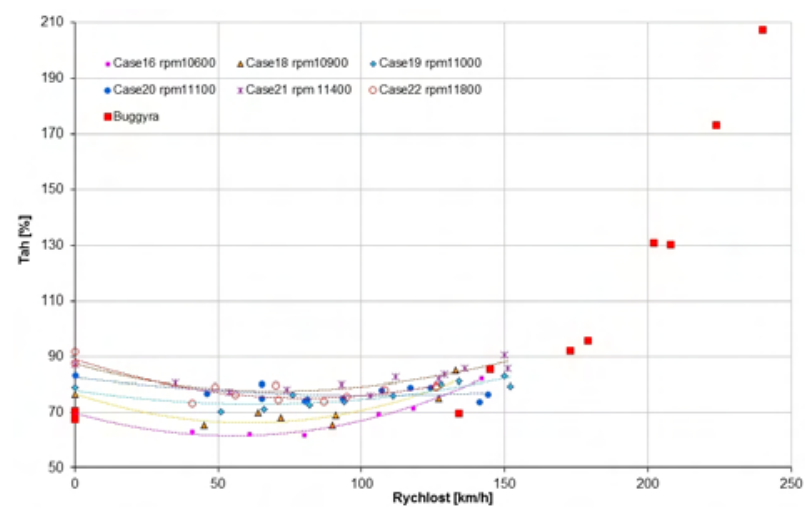

Figure 9: Thrust characteristics measured for a mobile device.

purpose, it was necessary to carry out mobile tests of the propulsion unit.

The prototype of the propulsion unit described above was attached to a Ford F-350, which was able to drive with a load of about $500 \mathrm{~kg}$ at speeds over $100 \mathrm{~km} / \mathrm{h}$. The arrangement of the whole device is shown in Fig. 7. A speed of only $140 \mathrm{~km} / \mathrm{h}$ was reached with this arrangement. This was only a half of the expected maximum speed of the aircraft, and was even lower than the cruising speed. It was necessary to find some other device that would be able to drive much faster and carry such a heavy load. There was practically only one possible way to achieve higher speeds on a ground device. The propulsion unit was placed on a Buggyra racing truck. The speed reached in this arrangement was $245 \mathrm{~km} / \mathrm{h}$. This arrangement is shown in Fig. 8. The forces on the test bed in the direction of the thrust were measured in both cases in a way similar to the tests performed by planchettes with a tensometrical gauge during the static tests.

It became evident when evaluating the measurement results that this force measurement method and our own testing method were inappropriate. Very intense vibrations were transmitted from the car into the test bed, and it was very complicated to filter them

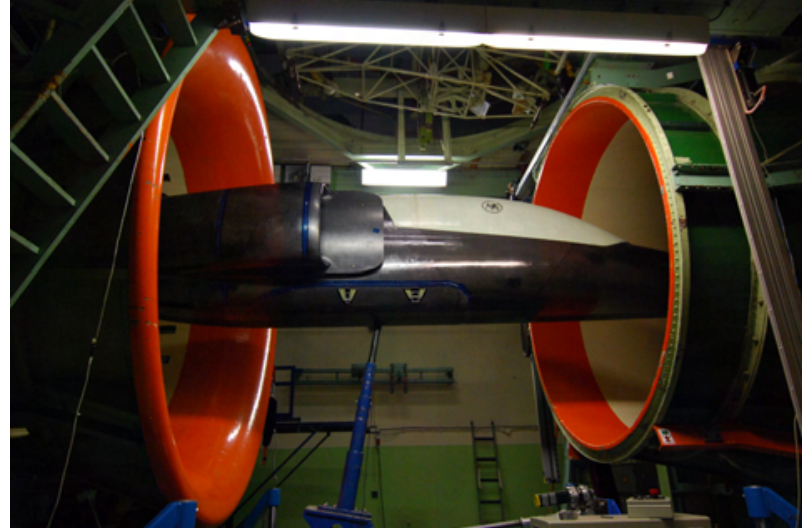

Figure 10: Fuselage demonstrator placed in an aerodynamic tunnel.

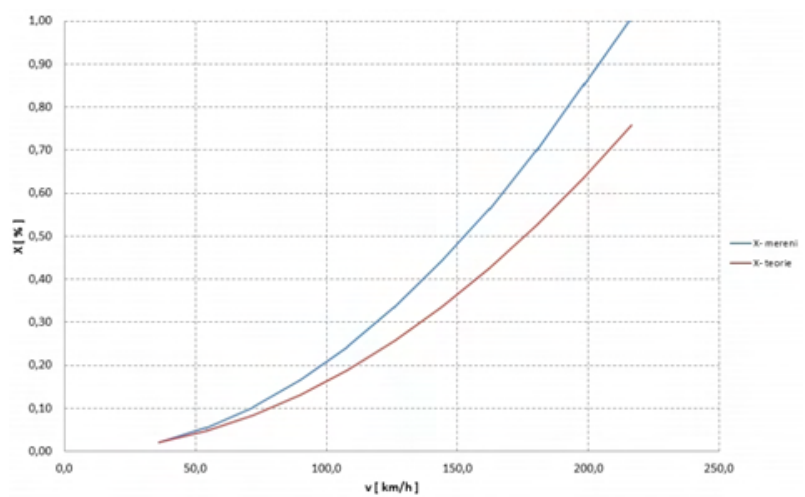

Figure 11: A comparison between theory and experiment.

out. The vibrations were primarily caused by the test bed-car connection, which was practically fixed. The measured values could be considered acceptable, after filtering, only for speeds of about $100 \mathrm{~km} / \mathrm{h}$, because at higher speeds the aerodynamic drag of the measuring device became more dominant than the thrust of the propulsion unit. This was due to the inappropriate shape of the test device, which had been primarily designed for static tests in a laboratory, and was not shaped for mobile tests. Some measured thrusts of the propulsion unit according to speed are drawn in Fig. 9 (dimensionless).

The same problem would arise, of course, if we were to make an aerodynamically better shape of the device. Forces in the direction of the thrust will always be influenced by the drag of the device that is used. In relation to the difficulties when predicting the required and available thrust, as mentioned above, it was not possible to determine which part of the measured force was caused by thrust and which part was caused by drag. As a result of this reasoning, we came up with a certain modification to the methodology for determining the maximum speed, as mentioned above. This modification leads to the next step in the experimentation. The next and final step involved 
measuring a full-scale aircraft fuselage equipped with a functional propulsion unit in an aerodynamic tunnel.

The following procedure will work with experimentally obtained available thrust values. The maximum speed value will then be determined by the intersection of the curves of the available and required thrust (curves $\mathrm{Tp}$ and $\mathrm{Tv}$ ).

\subsection{Measuring with the fuselage demonstrator}

A fuselage demonstrator was made for the purposes of tunnel measurement and for testing the installation of a power plant in the fuselage. Before measuring the fuselage equipped with a functional propulsion unit, measurements were made in an aerodynamic tunnel of the fuselage without a propulsion unit in order to verify the possible positions of the fuselage in the tunnel and the correctness of the methodology. Before the measuments were made, the fuselage was hung up with tensometric weights in the 3-metre diameter aerodynamic tunnel at VZLÚ a.s. in Prague Letñany.

The method for hanging the fuselage in the tunnel is shown in Fig. 10. The measurements in the tunnel were performed for speeds from 0 to $216 \mathrm{~km} / \mathrm{h}$.

In this area, too, our aircraft is a pioneer. It is practically the first ultralight aircraft to be tested in an aerodynamic tunnel, and it is the first aircraft in the Czech Republic for which full-scale measurements have been performed (with the exception of unmanned aerial vehicles).

To verify the fuselage drag force values obtained in the tests in the aerodynamic tunnel, a comparison was made with values obtained from the theoretical calculations performed in [2]. This comparison is presented in Fig. 11. A comparison of the dependencies shows clearly that the value obtained by measuring is bigger by about $25 \%$ at maximum speed.

Some part of this difference can be assigned to several gaps on the fuselage, which are perpendicular to the air flow (Aircraft drag can generally be increased by $10 \%$ due to this phenomenon). The greatest part will be caused by differences between the flux in a free stream and the stream in the tunnel, the major part of which is filled by the measured object. Even after eliminating these influences, a difference will remain between the theoretical results and the experimental results, even without the propulsion unit running, which will further strongly influence the results.

\subsection{Focus for further work}

As a next step, we will work on supplementing the fuselage demonstrator with a functional propulsion unit, and tests will then be carried out in an aerodynamic tunnel. To evaluate the measurements, we will prepare correction coefficients for converting the values obtained by measurements in the tunnel for movement in a free stream, and we will correlate the experiment with theoretically obtained values. Based on the experience gained in the tests and from the comparison with theory, we will compile a methodology for determining the available and required thrust, which can then be used for other aircraft based on a similar concept.

\section{Conclusion}

Many problems have arisen in the course of developing this aircraft that have not previously been investigated in the ultralight weight category. This is primarily due to the revolutionary concept of the UL-39 aircraft. Some of the problems that have been investigated are indicated in this paper. Especially problems with thrust characteristics, to which we have given the most space in this paper, have good potential to form the basis for further theoretical and experimental work. This work, in turn, will be highly beneficial for the future development of aircraft in the ultralight weight category.

Optimization of the propulsion unit, which is unique not only in the ultralight category, has a long way to go before serial production can be considered.

\section{References}

[1] J. Brabec. Koncepční studie letounu UL-39. Technická zpráva, TZP/ULT/72/11, Ústav letadlové techniky, ČVUT v Praze, 2011.

[2] J. Brabec. Aerodynamický výpočet letounu UL39. Technická zpráva, TZP/ULT/8/11, Ústav letadlové techniky, ČVUT v Praze, 2011.

[3] M. Helmich. Uspořádání pohonné jednotku letounu UL-39. Technická zpráva, TZP/ULT/68/2011, Ústav letadlové techniky, ČVUT v Praze, 2011.

[4] S. F. Hoerner. Fluid-Dynamic Drag. Published by the author, 1965.

[5] J. Roskam. Airplane design: Part VI: preliminary calculation of aerodynamic, thrust and power characteristics. The University of Kansas, 1987.

[6] R. Theiner. Studie nekonvenčního UL letounu. PhD thesis, ČVUT v Praze, 2007.

[7] E. Torenbeek. Synthesis of subsonic airplane design. Delft University Press, 1976. 